\section{Accounts of infant-feeding advice received by mothers: Queensland, Australia, 1945-1965}

\author{
Virginia Thorley \\ School of History, Philosophy, Religion \& \\ Classics, The University of Queensland, \\ Australia
}

\section{Abstract}

In the period 1945-1965 most women in the state of Queensland, Australia, gave birth in hospitals and thereafter they used a variety of services and individuals for advice on infant feeding. The services available were similar throughout the period. As mothers rarely worked outside the home, being good mothers was important to their identity. In this historical study, telephone interviews and written responses involving 44 mothers and former nurses from every region of this geographically vast state were used in order to investigate sources of personal advice on infant feeding used during this period, mothers' experience relating to this advice, and the extent to which they followed the advice. The free, nurse-run well-baby clinics and related services conducted by the state's Maternal and Child Welfare service were the most commonly mentioned services. However, the uptake of advice from this source showed considerable variation as women also drew upon family members, their general practitioners, advice columns, radio broadcasts, other mothers and their own judgment. Only rarely was a specialist pediatrician consulted. A minority of mothers was advised by pharmacists, private baby nurses, or entered residential mothercraft facilities. An important finding is that attendance at the baby clinics did not necessarily equate with compliance, especially as mothers became more experienced.

\section{Introduction}

This article, part of a larger historical study of infant feeding advice received by mothers in Queensland, Australia (Figure 1) in the two decades following World War II, ${ }^{1}$ will draw on interviews to identify and discuss the personal advice on infant feeding which postwar Queensland mothers received after their discharge from the maternity hospital. The sections of the larger study concerning mothers' experiences in the maternity hospitals and printed advice from diverse sources have been published elsewhere. ${ }^{2-4}$

As in other states, professional oversight of feeding healthy babies was largely the preserve of female nurses, rather than the medical profession. The Maternal and Child Welfare (MCW) section of the state government's Department of Health and Home Affairs began decentralizing its baby clinics in 1942 to include most Brisbane suburbs and major country towns, and by August 1952 they totaled $219 .{ }^{5}$ Residential facilities were established at several sites for mothers and babies with feeding difficulties. For remote areas, the MCW established a Correspondence Section in 1941 and later a mobile clinic in a railroad car, staffed by a nurse, serviced western towns.

\section{Maternal and Child Welfare baby clinics}

The mothercraft system instituted by the Queensland MCW adapted the methods of New Zealander, Sir Truby King, and Dr Margaret Harper in Sydney. Queensland's first baby clinics were established in Brisbane in 1918. A training school for nurses was established in Brisbane in 1924 after senior nurses had investigated mothercraft training methods in Sydney and New Zealand. ${ }^{6}$ Mothercraft was a system of child care taught to nurses and mothers, in which the focus on measurement and timing was promoted as scientific, though at times this was based more on authoritative opinion than empirical evidence. ${ }^{1}$ Unlike in other states where voluntary organizations established these services, in Queensland the baby clinics were always funded and managed by the state government, whose policy was that welfare was a state responsibility.

Clinic sisters, as MCW nurses were called, were an elite group in nursing in Queensland. Until 1968 the minimum education level for trainees in general nursing or midwifery in Queensland was completion of primary school, ${ }^{8,9}$ though larger hospitals demanded a higher standard. However, for the MCW course the Queensland Junior Certificate (two years short of completion of high school) was mandatory. Applicants for MCW training were also required to hold general nursing and midwifery certificates, becoming triple-certificated nurses on graduation. Trained nurses were generally called Sister, but clinic nurses liked to be addressed as Miss [Surname]. These factors contributed to the respect MCW staff received in the nursing hierarchy in the 1950s and 1960s. ${ }^{1}$ Most clinic sisters were single during this period.

Attendance at the well-baby clinics was voluntary. However, mandatory notification of births to the sister-in-charge of the nearest baby clinic (or the correspondence service) gave the MCW at least initial contact with
Correspondence: Virginia Thorley, School of History, Philosophy, Religion \& Classics, The University of Queensland, Australia.

E-mail: v.thorley@uq.edu.au

Key words: infant feeding, breastfeeding, mater nal child health, Australia, twentieth century.

Received for publication: 29 October 2011.

Revision received: 25 October 2012.

Accepted for publication: 25 October 2012

This work is licensed under a Creative Commons Attribution NonCommercial 3.0 License (CC BYNC 3.0).

(C) Copyright V. Thorley, 2012

Licensee PAGEPress, Italy

Nursing Reports 2012; 2:e12

doi:10.4081/nursrep.2012.e12

Queensland mothers. ${ }^{10}$ Some mothers did not maintain contact, while others continued to attend with varying degrees of regularity. The baby's individual clinic record was issued to the mother at the first visit. At each visit the baby was weighed and examined and the mother given oral advice, which the clinic sister then wrote by hand into this booklet (Queensland MCW. Individual clinic booklets. Author's collection).

Mothers of the postwar period formed the second generation of women who attended the baby clinics; indeed, some participants were encouraged by their mothers to attend. Others attended primarily because their own mothers were not available.

\section{Infant-feeding trends}

In 1945 most Queensland women at least began breastfeeding, but during this period breastfeeding rates steadily declined, particularly the duration of breastfeeding. ${ }^{11}$ Indeed, through the 1950s and 1960s breastfeeding rates fell markedly across Australia ${ }^{12}$ (Figure 2).

In Queensland in the 1940-1945 period, the average duration of full or unsupplemented breastfeeding was about 17 weeks, but by 1960-64 it had fallen below 10 weeks. ${ }^{11}$ The term full breastfeeding meant that no animal milk was given. It did not necessarily mean exclusive breastfeeding, for clinic sisters instructed mothers to give fruit juice and Vegemite (a highly salted yeast extract) in water, by bottle, from the early weeks (Queensland MCW. Individual clinic booklets. Author's collection). Money was scarce in the immediate postwar years, ${ }^{13}$ and mothers who bottle-fed often used home-modified cow's or goat's milk, rather than proprietary foods. By the 1960s their choices had widened to reflect an increase in available brands of artificial baby milks and more spending power. 


\section{Literature review}

Patrick provides a context for the beginnings of the MCW service in Queensland in his History of Health and Medicine in Queensland, ${ }^{8}$ which is supported by information from the official Queensland Year Books, ${ }^{10}$ Murphy's overview of the MCW service's early years, ${ }^{6}$ and McFarlane's account of the first 50 years. ${ }^{14}$ Gregory's history of nursing care and conditions at the state's largest hospital, ${ }^{9}$ and Thorley's discussion of conditions experienced by mothers, midwives and trainees in maternity hospitals throughout Queensland, ${ }^{2,3}$ provide further background. Siskind and colleagues, ${ }^{11}$ and Lund-Adams and Heywood, ${ }^{12}$ provide infant-feeding statistics for this period. Selby describes state health policy and the funding of health services for mothers and babies through the state government's purchase of a lottery, the Golden Casket Art Union, ${ }^{15,16}$ while Thorley has discussed the Labor government's reluctance to allow involvement in health and welfare by the volunteer sector. ${ }^{7}$ Other material consulted includes the memoir of a nurse who worked in the most northerly baby clinic in Queensland, on Thursday Island. ${ }^{17}$

Compliance is a term sometimes used in discussing adherence to professional advice. Snelgrove acknowledges that the term compliance is controversial in nursing literature today because it implies paternalism, assuming a passive patient, rather than a patient having agency. She defines non-compliance as patients' failure to follow the advice of health professionals. ${ }^{18}$ Failure to follow advice is prevalent and she cites estimates of non-compliance across various health areas ranging from 35 to $80 \%$. Important factors that Reibel describes that affect compliance are the individual's competing priorities, and communica- tions issues..$^{19}$ The latter include impact of communication, the use of active listening, and respect for independence in decision-making. Alaszewski acknowledges that patients actively seek information from multiple sources and recommends that, when they have not followed the information provided, providers should consider better communication modes. ${ }^{20}$

Particularly relevant to the present study is Selby's discussion of attitudes towards the MCW service by women of the previous generation and the extent of their divergence from the clinic methods. ${ }^{21,22}$ Mein Smith describes the influence of economic and social factors elsewhere in Australia on mothers' ability to follow complex routines, and the increased confidence of mothers of more than two children in making their own decisions. ${ }^{23,24}$ In essence, she states emphatically, prescriptions are not the same as practices.$^{23}$ These studies and the experiences described here contradict the credit the annual reports of the MCW by successive Ministers for Health and Home Affairs gave to the influence of the baby clinics for the low infant mortality (Thearle MJ, unpublished paper, 1987). ${ }^{5}$ In fact, the largest decline in infant mortality in any decade occurred in the period to 1910 , predating the establishment of the baby clinics in $1918 .{ }^{25}$

\section{Aims and objectives}

This paper identifies the sources of personal advice on infant feeding that mothers of the 1945-1965 period accessed after their discharge from the maternity hospital, and examines their experiences and the extent of their uptake of that advice. Thus this paper provides a snapshot of the interaction between mothers and those who advised them at a time when advice was more prescriptive than it became latterly.

\section{Materials and Methods}

The information presented here is drawn from 44 of the 48 women interviewed in 19981999 for the larger study on advice that Queensland mothers received on infant feeding. ${ }^{1}$ Most respondents were self-selected, responding to a letter published in three newspapers. To fill gaps in representation, the author contacted an Aboriginal health worker who was a mother during the study period, a former Government Nurse in the Torres Strait and a mother from an immigrant background. Although mothers are the primary participants, interviews with 10 nurses are important as they verify or expand on the mothers' accounts (Table 1). The participants provided consent, which was dated, were free to withdraw at any time, and were de-identified to preserve anonymity. The raw data was stored separately from the deidentified material. The participants represent-

Table 1. The participants. Category of respondent Number

\section{Respondents cited}

$\begin{array}{lc}\text { Mothers } & 36 \\ \text { Nurses } & 10 \\ \text { Untrained Torres Strait } & 1\end{array}$

\section{Government Nurse}

\begin{tabular}{lc} 
Sub total & 47 \\
\hline Overlap (responded in 2 categories) & -3 \\
Total individual respondents & 44
\end{tabular}

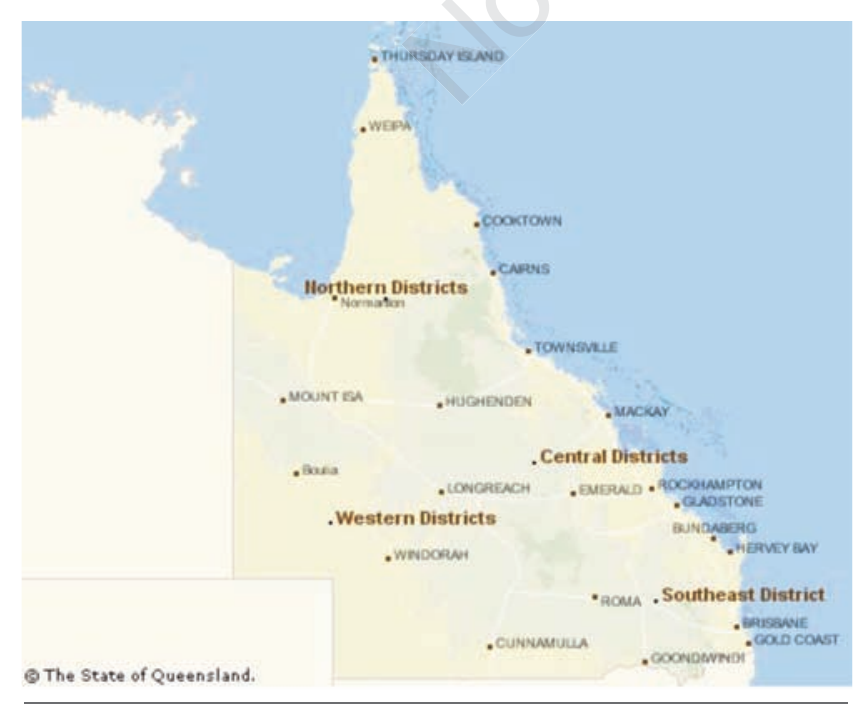

Figure 1. Map of Queensland (C) The State of Queensland, with permission).

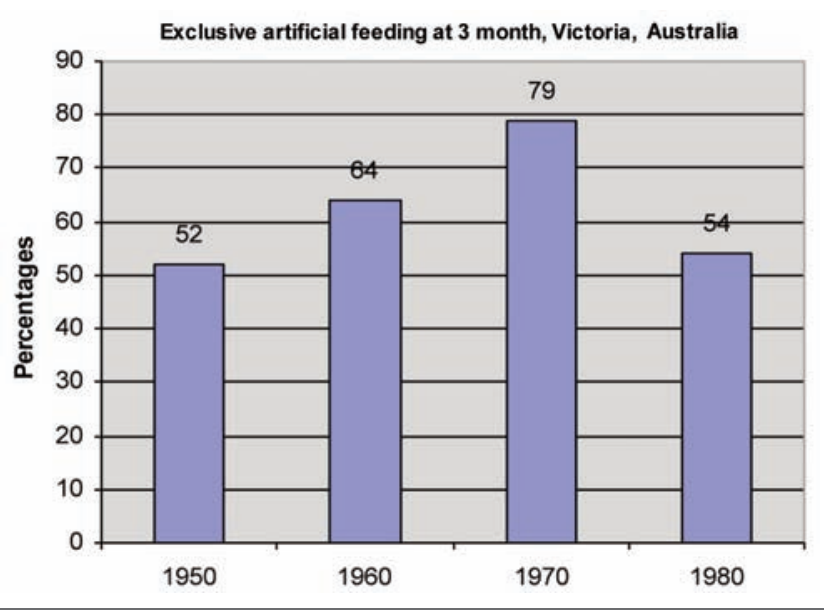

Figure 2. Predominance of exclusive artificial feeding at 3 months in Australia, after 1950; figures are calculated from data from the state of Victorian, for which more regular figures are available. (Adapted from Thorley V. PhD thesis, University of Queensland, 2007). 
ed most regions of the vast state, from the Torres Strait islands in the far north, to the more closely settled south-east corner surrounding Brisbane, the farming regions of the Darling Downs (west of Brisbane) and the Atherton Tableland (Figure 2) and (in the north), large coastal towns, and the arid north-west and south-west.

The 1945-1965 period was chosen because mothers and nurses from this period were available for interview and common features applied in 1965 and 1945. These were, firstly, the situation of women as primarily homemakers, for women generally lost their jobs on marriage. Thus women measured their worth on their ability to be good wives and mothers. Secondly, these were the mothers of the baby boom, the postwar rise in the birthrate, which only ended in the mid-1960s. ${ }^{1,25-28}$ Finally, after the expansion of the free MCW clinics in the early-1940s, mothers in 1945 had similar access as mothers in the 1960 s.

\section{Results}

\section{The baby clinics and women's compliance}

While the source of one-on-one advice most commonly cited by the mothers was the MCW clinics, this advice was not, however, received in isolation. Other sources of advice included: a mother or mother-in-law; general practitioners (GPs) and specialist pediatricians; a pharmacist husband; residential mothercraft centers immediately after hospital discharge; other mothers waiting to see the nurse; newspaper or radio advice from Lady Cilento, a leading GP; or their own common sense (Dr Phyllis Cilento became Lady Cilento after her husband was knighted). A private baby clinic, nurses at the Children's Hospital, and the Lactogen nurse were each mentioned once (Table 2).

The extent to which mothers followed or adapted the clinic advice emerged as an important issue. Most former clinic sisters interviewed believed that mothers complied, simply because they seldom told the clinic staff when they diverged from the advice. However, a 1963 graduate of the MCW training course reflected very closely what mothers reported. She believed that some mothers followed the advice assiduously, others attended the clinic only to have the baby weighed, while others turned to the clinic sister to discuss personal problems (p 136). ${ }^{1}$ Some women admitted that their levels of compliance changed as they gained confidence as mothers (Table 3 ). The interviews support Selby's contention that the belief of health authorities that attendance equated with compliance is over-optimistic,,$^{21,22}$

Table 2. Sources consulted by the 43 mothers for infant-feeding advice (excepting print materials and radio programs).

\begin{tabular}{lc} 
Facility or professional category & Frequency cited ${ }^{*}$ \\
MCW baby clinics & 36 (includes even minimal contact) \\
Family (mother, mother-in-law, & 9 (probably underreported) \\
sister, spouse, father-in-law) & \\
\hline Medical doctor & 11 \\
$\quad$ General practitioner & 2 \\
Pediatrician & 1 \\
$\quad$ Dermatologist & 2 \\
Pharmacist ${ }^{\sharp}$ & 1 \\
Children's Hospital nurses & 1 \\
Lady Cilento Hostel \& After-Care Home & 1 \\
\hline MCW home & \\
Private service/baby clinic & 1 \\
Sister Robinson & 1 \\
Nestlé (Lactogen nurse)
\end{tabular}

MCW, Maternal and Child Welfare. *Some of the mothers cited more than one source of advice. Mothers have been counted, rather than infants; ${ }^{\circ}$ Most Queensland mothers were exposed to the Maternal and Child Welfare (MCW) clinics, even if they did not attend after first contact. Services accessed were predominantly well-baby clinics, and some mothers additionally mentioned using the correspondence service and the MCW handbook; *The two mothers who cited pharmacists as advice sources each had a pharmacist husband, and one of these women also received advice from her pharmacist father-in-law; ${ }^{\S}$ One mother, with two experiences.

and Mein Smith's observation that instructions may not be followed in practice. ${ }^{23}$

The level of non-compliance with baby clinic advice is higher than Selby's results of 40 per cent non-compliance for mothers whose babies were born in the 1920 s and 1930s and who attended the clinics ${ }^{21}$ (Table 3). Allowing for non-attendees as well, in a later paper from the same data Selby calculated that nearly twothirds of mothers with clinic access either did not attend or followed their own judgment. ${ }^{22}$ Of the 21 mothers in the present study who addressed the issue of adherence to clinic advice, three were emphatic about not attending (one of these after initial attendance), two were emphatic about not following the advice, and nine admitted adapting the advice, particularly for a subsequent baby. Some mothers initially claimed they followed the advice exactly, but contradicted themselves when answering open-ended questions, admitting they disregarded the advice in at least some respects. ${ }^{1}$ Some mothers adapted the advice using their own judgment; others heeded their mothers, mothers-in-laws, or family doctors. Thus, fourteen, or two-thirds, of those who specifically addressed this issue diverged from the clinic advice to a greater or lesser extent, even if they followed it initially. It is unlikely that the mothers who failed to answer this question followed clinic advice, but only those mothers who addressed this question were included in this analysis of compliance.

\section{Social reasons for clinic attendance}

For mothers isolated at home with a baby, such as the mother of four children born between 1945 and 1956, the clinic visit was a social outing, providing the opportunity to
Table 3. Compliance with Maternal and Child Welfare advice.

\begin{tabular}{lc} 
Category & $\begin{array}{c}\text { Number } \\
(\%)\end{array}$ \\
Non-compliance or only partial & \\
compliance & \\
Non-attendee at baby clinics* & $3(14.3)$ \\
Emphatic about disregarding advice & $2(9.5)$ \\
Admitted adapting advice & $9(42.9)$ \\
Total & $14(66.7)$ \\
\hline Claimed to follow advice & $7(33.3)$ \\
Total who responded about compliance & $21(100)$ \\
\hline${ }^{*}$ Attended not at all, or ceased after brief initial contact.
\end{tabular}

meet other mothers as well as consulting the sister. A mother whose babies were born in 1950 and 1953 always dressed in her best to go to the clinic. Another mother considered meeting other mothers and discussing their babies' progress was a benefit of clinic attendance. For another mother, isolation from family and friends in a western town when her husband was away during the week made the arrival of the clinic sister particularly reassuring, by providing human contact as well as advice. She was feeding her baby on Lactogen and felt lonely and frightened when her daughter became constipated, till the clinic sister arrived from Roma, administered an enema and adjusted her feeding.

Women interviewed held a variety of views about the advice from the clinic sisters. Those who attended more than one baby clinic noticed that attitudes differed between the sisters, providing different experiences. If they resented a particular sister's manner they usu- 
ally stopped attending, rather than disagree with her. This generation rarely challenged advice provided by authority figures ${ }^{3}$ and some new mothers were grateful for prescriptive advice. A few mothers expressed strongly favorable views of the clinic advice. Although some mothers suggested that the sisters could be authoritarian or possessive of the child, generally they had moderately favorable views about how they were treated on clinic visits, describing staff as friendly and helpful. ${ }^{1}$

\section{Inexperienced mothers}

Regular attendance was more likely with firstborn babies, especially if the grandmothers were dead, absent, or had never breastfed. A number of interviewees lacked experience with handling babies. One such mother's first baby had been born small-for-dates and Brisbane's Fortitude Valley (the Valley) clinic provided specialized follow-up care. Reassured by the nurses' kindly assistance, through the 1950s she travelled by ferry to take her other four babies to the same clinic. Another inexperienced mother initially received help from her doctor, who referred her to the Valley clinic, where she followed the advice for nine months; however, she found this difficult to do with her second baby. An English mother whose three children were born between 1956 and 1962 depended for advice upon a Brisbane MCW clinic and her pharmacist husband. ${ }^{1}$

Some mothers who were initially dubious about following clinic advice changed their minds. After initial misgivings a Brisbane mother ended up believing in its rightness. She believed that self-demand feeding would not rest a baby's stomach, though why the infant stomach needed to be rested was not stated. She remembered the instructions as: Breastfeed as long as possible. Feed baby - bring up its wind - put down to sleep. Do not nurse [cuddle] to sleep. If it cried make sure it was comfortable... let it cry a little to exercise lungs. No dummy Ipacifier] (p 140). ${ }^{1}$ Initially she considered the regimen harsh, but later decided it was good discipline. So she followed the advice for all six babies, born between 1949 and 1956, crediting it for her well-behaved children. Similarly, a young Townsville mother avoided the baby clinics with her first baby because of negative reports from friends. She received advice on breastfeeding from a hospital midwife, her GP, and the Truby King Mothercraft book. However, she took her second baby, a projectile vomiter, to the local baby clinic and followed the nurse's advice exactly, until her baby rejected the recommended egg yolk in any form. She breastfed for six months, then supplemented until she gradually weaned.

Some mothers had positive memories of their relationships with the sisters despite seeking other advice. One, herself a nurse, attended the baby clinics on Thursday Island (1964) and in Cairns (1966). Her mother lived interstate and so she turned to her GP, other mothers, the clinic and magazines for support. Her doctor advised her to wean her baby, without advising what to give. The clinic sisters on Thursday Island and in Cairns were friendly, but too young and inexperienced to help.

\section{Gaining experience: adapting clinic advice}

Mothers who complied with the prescriptive baby clinic advice with the first baby often quietly adapted the advice with subsequent babies or attended only to have the baby weighed. Some attended the clinics regularly, following the advice to some extent and blending it with their own common sense. These mothers recalled the clinic experience favorably and felt it increased their confidence. They felt encouraged when the baby's weight met the sister's approval and they were told they were doing a good job. One of these mothers considered the MCW handbook, Care of Mother and Child, ${ }^{29}$ such a helpful resource that she kept it all her life. She deviated from the clinic advice by ignoring the recommended age of nine months for weaning from the breast. Three of her four babies were weaned at 10,14 and 12 months, respectively.

Typical of mothers who followed the clinic policies for the first baby and common sense and experience for the others was a Darling Downs mother of five. A mother whose first baby was born in the provincial city of Rockhampton in 1941, and the other five in Brisbane between 1944 and 1957, eventually learnt to trust her own judgment and feed her babies when they were hungry. She disagreed with the clinic nurses' insistence on the same feeding schedule for all babies, irrespective of size, and did not attend after her second baby.

Sometimes mothers wanted to present themselves as good mothers who followed the clinic advice, but then revealed that they had diverged from this advice, sometimes in significant ways. A former nurse, whose babies were born between 1948 and 1956 in Brisbane, Gympie and Charters Towers, initially rated the baby clinic advice highly as she lacked experience. Nevertheless, although she claimed that she assiduously adhered to the clinic advice, her other answers indicate she regularly ignored key points of the advice. She considered the sisters authoritarian when her 1948 baby gained 1 $\mathrm{lb}$ a week at one stage and they criticized her for overfeeding. Consequently, I did not go every week as I had my own scales. [I] only went to find out about extra food to give... I allowed the baby to change over to $5 \times 4$ [hourly] feeds a day even before $10 \mathrm{lb}$ [weight was] reached and didn't tell Clinic Sister!!! ... [My 1957] experience at the Clinic was traumatic! I knew I had sufficient milk, but it didn't 'come in' as it usually did when I fed. I ignored the [test feed] result!!! ... I used to pick the babies up always when they cried - against advice - but they didn't get 'spoilt' and grew up as loving persons I think as a result (pp 146-147). ${ }^{1}$

Her own mother had never breastfed her four children, but she herself not only breastfed successfully, but after her first baby was born donated her excess breastmilk to premature babies in the hospital. Her mother's letters supported her mothering style; in contrast, her mother-in-law considered her too rigid, but this criticism seems unjustified.

Another Darling Downs mother, who gave birth to six children between 1950 and 1959, drew on the baby clinics, the MCW Correspondence Section and Care of Mother and Child for advice. Her own mother had never breastfed, but she and her husband believed in breastfeeding. She always had plenty of milk and breastfed all six of her babies, the second with complementary feeds for eight months. At first she lacked confidence to manage without direction and trusted the clinic sisters' advice as she believed that mothers' ideas were antiquated. She admitted adapting the advice as her confidence grew.

Other mothers listened to advice from all quarters and then used their own judgment. A Brisbane mother of four children, born between 1953 and 1959, listened to a wide range of advice but ultimately followed her own judgment. She accessed advice from the baby clinic, her mother and mother-in-law, her doctor, books, and Lady Cilento's Medical Mother column and radio program. ${ }^{30}$ Another Brisbane mother whose three babies were born in private hospitals, the last in 1945, used similar sources of advice, but made up her own mind. She attended the clinic mainly to weigh her babies. She viewed her babies as individuals and, contrary to clinic policy, she fed on demand and used the breast for comfort as well as food. Perhaps because of this flexibility, she enjoyed breastfeeding and did so for nine months. While relatively happy with the clinic service, attempts by some individual clinic nurses to control by inducing guilt is implied in her recollection that when baby had not gained weight you got into trouble as if you were a criminal not looking after baby. High praise was given when you did what they said to do (p 148). ${ }^{1}$

Listening to advice and then making up her own mind was the practice of another Brisbane mother of three babies born between 1955 and 1959. She remembers the clinic staff as friendly. She believed the recommended egg yolk and orange juice disagreed with her child and used her own discretion in relation to introducing solids (complementary foods). Her first baby was breastfed for eight months, during which time she attended the clinic, attending for shorter periods with subsequent babies. She 
weaned onto infant formula and introduced straight cow's milk only after the babies were a year old, on her husband's advice. She weaned her second baby at six weeks after she contracted a staphylococcal skin infection, while her third was weaned at three months after unresolved problems with her milk supply.

An interstate mother whose last four children were born in Brisbane, also visited the MCW clinics regularly but followed her own judgment. Her first baby failed to regain birth weight by age six weeks, and with her second baby she ignored specific advice to give him 4 oz $(120 \mathrm{~mL})$ by bottle after the breastfeed, giving him much more. Like other mothers interviewed, she contrasted clinic sisters' lack of personal experience of rearing babies with her own mother's considerable personal experience. A Brisbane mother whose last baby was born in 1945 remembered the clinic instructions to let her baby cry, not to pick him up and to take him for walks in the pram. She disregarded some of this advice, as she considered each child an individual and believed love and time spent with the babies was important.

Some mothers disregarded specific MCH advice altogether. In the 1960s in Cairns in the far north, young mothers vied with each other over how young their babies were when solids (complementary foods) were introduced (range 2-12 weeks) - and they never told the clinic sister.

A former teacher who gave birth in the Brisbane Women's Hospital in 1949 after a difficult birth made the 12-h round trip from the family farm to Brisbane to attend the Fortitude Valley baby clinic. In her opinion: The Clinic sisters were unmarried, middle aged women with very little patience and all babes were to conform to a strict pattern. Mostly young mothers were reduced to tears - made to feel incompetent - the baby had taken too much at a test feed - the baby had gained far too much weight... (p 153) $)^{1}$ A strong milk ejection reflex made her milk spurt out for months. She predominantly breastfed, apart from giving her baby cod liver oil, diluted orange juice and Vegemite, and introduced baby cereal around four months. With subsequent babies she avoided the MCW clinics and had her babies weighed at a pharmacy. She recalled that her friends had similar experiences and stayed away from the clinics. A physiotherapist also initially turned to the clinics for advice. She never achieved her goal of breastfeeding for nine months and her babies were weaned at three or four months, two of them after combining breast and bottle. She began full artificial feeding with eight bottles a day, more than the five a day which Care of Mother and Child recommended, and gradually reduced the number. Thus both these educated mothers eventually followed their own judgment, without confronting the sisters.

\section{Negative opinions}

Like the former teacher, some mothers perceived their experience of the clinic sisters as negative overall. One such mother, whose only child was born in Brisbane in 1959, listed her mother, the clinics and the Medical Mother column as her sources of advice. She considered the staff at the one baby clinic she attended authoritarian and unwilling to listen to her pleas for help. She did not comply with the advice from the clinic, believing it had a negative outcome. Her mother was her main influence, advising her that if she became upset she would lose her milk. So it is unsurprising that she artificially fed her baby.

A Mount Isa mother also considered her experience negative. In this remote mining town where women were isolated from their extended families, the staff profile at the two baby clinics differed markedly. The 'mineside clinic' was O.K. the Sisters were married women. I could not attend it as I had no transport. The Maternal and Child Welfare Clinic was within walking distance. All the Sisters at this Clinic were old maids[;] one was all right but [the] other was completely unsympathetic [if] my baby did not weigh enough. ... the sister, though kind enough, squeezed my breast and said 'You haven't got much milk have you?' This dampened my spirits even more, because I had to push a pram for a mile to get there... ${ }^{1}$ This mother followed the MCW clinic advice, supplementing breastfeeding with modified goat's milk, which she believed made her daughter constipated.

A clinic sister who took several years out of the workforce to have her own children supports these views: Some new mothers/fathers felt that some of the elderly single sisters did not understand their problems and were much too rigid with dos and don'ts. Advice was sometimes given more like an order than as advice (p 155). ${ }^{1}$

A mother whose only baby was born in Maryborough in 1947 had her mother's help for five weeks and it was only after this that her milk dried up. In Brisbane at the Woolloongabba clinic she was advised to massage her breasts and limit feeds to the required schedule; this did nothing for her milk supply and the authoritarian sister-in-charge upset her. Attending the Woolloongabba clinic involved a long walk pushing a pram and she did this for just one week. In desperation she bought a tin of Lactogen and Pentavite drops and thereafter entirely followed her own judgment.

Other mothers also felt intimidated by particular sisters and reported ceasing attendance or changing to another clinic, rather than disagreeing. There was a dragon of a sister, recalled a Brisbane north-side mother, but she had no family in Queensland to turn to for advice. Authoritarian was the word for the sister... I wouldn't have dared go against what she told me (p 156). ${ }^{1}$ She took her second baby, born in 1953, to a different suburban clinic with more approachable staff, and she attended this clinic regularly, following the advice given.

\section{The clinics and breastfeeding}

Although most mothers began breastfeeding, fewer continued after the late-1950s. MCW policy supported breastfeeding for nine months, but clinic advice did not necessarily result in the desired outcome. A Brisbane mother of the early-1950s reported good results. After a traumatic birth, she fed her son by both breast and bottle for three months, after which she was able to discontinue bottle feeds. She attributes her improved lactation to the clinic advice to splash her breasts with alternate hot and cold water to provide stimulation. A contributory factor was her son's recovery from facial damage from his difficult instrumental birth, which had affected his feeding. Both her babies were weaned at nine months. Another Brisbane mother whose first baby was born in 1957 believed that every mother could produce sufficient milk for her baby. She expected to breastfeed for the recommended nine months and was disappointed at only partly breastfeeding. She regretted not receiving more help from busy hospital staff to establish her milk supply. As she was inexperienced and she found the clinic sisters friendly, she attended regularly. The decision that her supply was inadequate was based on the thencurrent practice of a single test feed during the day, that is, weighing the baby in the same clothes before and after the feed.

Like other mothers and nurses during the post-war period, this mother assumed that test feeds were the only way that sufficiency of intake could be determined. This process probably underestimated daily milk yield, through maternal stress and the then-current belief that all feeds were equal in volume. Isbister, a Sydney pediatrician who had conducted research on the milk ejection reflex, wrote in the Medical Journal of Australia in 1954: Single test weighs are often fallacious and have been the cause of weaning many babies unnecessarily. The mother goes to the health centre for a 'test weigh' much as she would to an examination, and anxiety and unfamiliar surroundings often inhibit the draught Imilk ejection] reflex. ${ }^{31}$

Mothers agreed that clinic sisters never suggested increasing the number of breastfeeds per $24 \mathrm{~h}$ and allowing the baby longer at the breast to stimulate milk yield, instead of limiting feeds to ten min each side. Instead, the mothers were advised to drink plenty of water and a powdered chocolate supplement mixed into a glass of cow's milk. This mother drank it for three months, to no avail. In Isbister's opinion: There is no evidence that any of the much 
advertised proprietary products for stimulating milk production are effective in any other way than psychologically. ${ }^{31}$ This mother partly breastfed her first and third babies for three months. Her second baby, born in 1959, had already regained his birth weight before leaving hospital and was breastfed for four-and-ahalf months, which she enjoyed. The last baby, born in 1962, was a projectile vomiter and a proprietary infant formula, Synthetic Milk Adapted (S.M.A.), was used as a supplement. S.M.A. had come onto the Australian market in $1958 .^{32}$ Despite these difficulties, this mother did the best that she could with the advice she had. Besides using the baby clinics for advice on feeding, she read widely and found Lady Cilento's newspaper articles practical.

\section{Others consulted by mothers}

\section{Grandmothers, family and clinic advice}

Even if their own mothers could provide support, some respondents depended mainly on the baby clinics, or combined both forms of support. Few of the women interviewed used family advice without at least some clinic attendance, though one mother reported her sources of advice as her mother for the first baby and after that she followed her own counsel. The tendency to combine the support of family members along with the advice of clinic nurses applied whether the mothers lived in Brisbane or in country areas. Factors in clinic attendance that mothers mentioned as being reassuring were: checking that the baby was gaining weight, continuity of care, and advice about the supplements and products recommended.

A knowledgeable family member could give confidence, as the experiences of an Aboriginal mother and the daughter of Greek immigrants illustrate. The Aboriginal mother attended the Cloncurry baby clinic in northwest Queensland and considered the sisters good in the late-1950s and early-1960s, but less so later. She followed some of the advice from the clinic sister, but took her mother-in-law's advice to feed the baby when he was hungry instead of scheduling feeds. Her babies were weaned onto Sunshine full-cream powdered milk at around 12 months, with Pentavite vitamin drops. She bought Sunshine milk because the whole family could use it, unlike the more expensive Lactogen. The daughter of Greek immigrants, whose first baby was born in the 1950 s in a small town, learnt by example how to breastfeed through living with her older sister when the latter was a new mother. So she had little need to seek information elsewhere and attended the baby clinic mainly to check her baby's weight. The baby care ideas she followed were a blend of Greek and Australian; that is, learning from family example while taking only what she wanted of the clinic advice.

\section{Private doctors, pharmacists, and private baby clinics}

Some mothers consulted their GPs as well as attending the baby clinics, or sought medical advice for specific matters. The mother who stayed in the Lady Cilento Mothercraft Hostel and After-Care Home also consulted Lady Cilento privately. She attended the MCW clinic, too, but measured the advice against what she had learnt from Lady Cilento. If her babies woke between 9 p.m. and 5 a.m., she gave them water, a practice in agreement with the MCW prohibition of milk feeds at night. The main sources of advice for another Brisbane mother were her husband and fatherin-law, both pharmacists, who provided pharmacy literature on artificial infant milks. The family doctor also provided advice.

Although her mother and grandmother lived interstate, a Darling Downs mother of eight children born between 1947 and 1961 never attended the baby clinics because she preferred her family doctor. In 1961, she was a regular listener to Lady Cilento's Medical Mother radio program. The instructions received and practiced during her hospital stay (then ten days) were a strong influence and so her babies were breastfed on a 4-h schedule, with warm water in between. Another Darling Downs mother, who complied with clinic advice for the first of her five babies, combined her own common sense with her family doctor's advice for subsequent babies. She struggled with feeding three of her babies partbreast, part-bottle in the early weeks, before switching to complete artificial feeding. She took her GP's advice and never put the third baby to the breast at all. Her fifth baby, a colicky child born in 1961, was unsettled on cow's milk or proprietary milks recommended by clinic staff, which indicates she did attend the clinic with this baby, even if not regularly. She then took her family doctor's advice to switch to S.M.A. and was pleased with the results.

Occasionally mothers were dissatisfied with medical advice. A Darling Downs mother explained: Regarding no comments about Doctors, my opinion of them is not high, having received very misleading advice on health matters other than breastfeeding where the children were concerned (p 157). ${ }^{1}$ A Brisbane mother who, unusually for the time, consulted a private pediatrician about feeding a healthy baby recalled that he just said to persist with what she was doing. As he never suggested a follow-up visit she lost confidence in him, not realizing that he was endorsing her common sense. Other respondents with sick babies under the care of pediatricians were grateful for their care.

Finding her own source of advice helped a Brisbane mother feel more confident. After the birth of her only child in a private hospital in 1948 , she received advice from three sources before settling on her own choice of whom to listen to. The uniformed nurse employed by Nestlé called, unexpectedly, at her home and handed her a metal measuring spoon for use with Lactogen. This nurse knew her personal details and address, but the mother never knew how this information had been obtained. She became dissatisfied with the baby clinic advice when breastfeeding to a schedule was unsuccessful and her daughter was constantly screaming. She began supplementing with Lactogen, recommended by the Lactogen nurse, but when the baby became constipated she added Milk of Magnesia to the bottle. She lacked confidence in a private nurse she employed to bath the baby and make up the bottles.

So she put her faith in Sister Robinson, who ran a private clinic in Albion, a Brisbane suburb. After a single test feed, Sister Robinson ruled out breastfeeding. She put the baby on home-modified cow's milk with instructions to use brown sugar if the baby became constipated and white sugar the rest of the time. This was similar to the MCW clinic advice on constipation in artificially fed infants, though MCW staff would additionally check the strength of the milk mixture and order boiled water and prune juice, as a number of respondents stated. Sister Robinson recommended solid foods at six weeks, unusually early for the time (1948). She instructed mothers to remove the less digestible, seedy core from a ripe Cavendish banana and discard it, before mashing the rest of the banana. Other solids prepared to Sister Robinson's recipes for very young babies included oatmeal jelly and wheat jelly, which required steaming for $3 \mathrm{~h}$ and tied the mother to the house (similar recipes were available from the MCW, but for older babies). These jellies were given with either banana or steamed apple. Sister Robinson believed that babies had dry mouths that required moistening before feeding and instructed mothers to give their babies a few sips of water before milk feeds. She recommended Dr Spock's book. ${ }^{33}$

\section{Relations between clinic nurses and doctors}

Some doctors considered infant feeding and baby care the preserve of the baby clinic sisters and sent their patients there; others were dismissive of them (pp 159-160). ${ }^{1}$ A mother who was critical of her doctor's infant-feeding advice observed that the doctors in Cairns distrusted MCW clinics. Another remarked that her doctor advised her to avoid the clinic. The reverse also happened, when clinic sisters defended their place in the health system. A mother whose babies were born in 1955 and 1957, and artificially fed, agreed with criticisms of medical staff by an older clinic sister at the Paddington clinic, who considered that 
doctors then were ill-equipped for giving infant-feeding advice. She also depended on practical advice from her mother. A Darling Downs mother also noticed that the sisters in the Miles and Toowoomba clinics in the 1950s had negative opinions of some doctors. The experience of a former baby clinic sister in the mid-1950s and mid-1970s was that some doctors respected clinic sisters, while others made fun of them. A respondent who graduated from the MCW course in 1963 agreed. She believed that, on infant-feeding matters, mothers generally had more confidence in advice from a clinic sister than from a GP (p 160). ${ }^{1}$

\section{Special groups}

\section{Indigenous mothers}

Australia's indigenous people could not vote until 1962, were not counted in the national Census until 1967 and were subject to discrimination. Some country hospitals in Queensland segregated indigenous women from other maternity patients; others did not. In their early days, baby clinics throughout Australia were intended to support the health of white children, but this had gradually changed. An Aboriginal mother from Cloncurry recalled that baby clinic staff treated Aboriginal and Caucasian mothers identically. Several of the baby clinic nurses interviewed reported that Australian Aboriginal mothers used the same facilities as Caucasian mothers and received the same care. Not everyone in the community appreciated her even-handed policy. A clinic sister who served in a number of small towns in the 1950s commented that her insistence on fairness caused her a certain amount of social isolation (p 145). ${ }^{1}$

Torres Strait Islanders, from the islands between the northern tip of Queensland and Papua New Guinea, are Australia's second indigenous group. Elizabeth Burchill, who arrived in 1959 to staff the Thursday Island baby clinic, wrote that, although she weighed the babies and advised the mothers, she thought they were well able to follow their own judgment. ${ }^{17}$ She described the babies as healthy, allergy-free and fast-growing. In the early-1960s, Islander mothers generally breastfeed for the first year, while their babies learned to eat local foods, such as steamed fish, rice and yams. A Caucasian mother who lived on Thursday Island also observed the Islander mothers' success with breastfeeding. According to Burchill, Torres Strait Islander babies who were bottle-fed took double the amount of milk usually calculated for weight and age. ${ }^{17}$

On some islands, health care was provided by the Government Nurse, a position automatically filled by the teacher's wife, always Caucasian. In 1967 the newly appointed Government Nurse on York Island received only three days' training at the Thursday Island Hospital. Support was available only by radio, using a chart and code to identify symptoms as taught during her three-day training. Pregnant women in their third trimester were required to move to Thursday Island, the site of the only hospital in the Torres Strait, but occasionally this system failed. The Government Nurse was permitted to give injections, but only to Torres Strait Islanders, and the medical equipment was of poor quality. Only three babies resided on the island during this Government Nurse's tenure, including healthy twins. Breastfeeding was culturally well supported by older female kin who assisted the mothers (pp 152-153). ${ }^{1}$

\section{After-care homes}

Two after-care homes existed during this period. Mothers able to afford the modest fee could enter the Mothercraft Hostel and AfterCare Home to learn baby care in a supportive environment after leaving the hospital. This facility was established in 1942 by the Mothercraft Association of Queensland (MAQ), a voluntary organization, in the Brisbane suburb of Clayfield. ${ }^{34}$ In 1947 it was renamed the Lady Cilento Hostel and AfterCare Home in honor of the MAQ's first president. The state government's MCW also operated residential homes, hospitals where mothers and babies, or sometimes just the babies, were admitted at no cost for management of feeding after discharge from the maternity hospital. ${ }^{7}$ Premature infants were also nursed in the MCW homes. Both the MCW and MAQ facilities employed triple-certificated sisters and provided training as mothercraft assistants for school leavers. ${ }^{35}$

A respondent whose mother had died spent three weeks in the Lady Cilento Mothercraft Hostel and After-Care Home in 1947 learning how to care for her baby daughter. She was taught to supplement her baby after each breastfeed, the last feed at night being at 9 o'clock. While in residence she increased her supply to some extent and continued to combine breastfeeding with a supplementary bottle for eleven weeks.

A mother who used the government's MCW mothercraft home at Clayfield on two occasions considered it a wonderful experience as she had confidence in the trained nurses. The MCW policy firmly discouraged night feeds, and the matron (director of nursing) of the home attributed her babies' nightly crying to a failing breastmilk supply. On the matron's recommendation, both babies were thereafter entirely bottle-fed. The matron was remembered warmly by one of her staff as someone who did her job with a lot of love and affection for the staff and mothers, and ran it like a home (p 161); ${ }^{1}$ which explains this mother's positive memories. Strict feeding schedules were applied in all MCW facilities and mothers were powerless to bend the rules in the institutional setting. Consequently, another respondent had her sick baby admitted to the baby's ward of the Children's Hospital in 1949, to avoid admission to the Clayfield MCW home.

Premature babies or those with digestive problems were fed as often as two hourly in the MCW homes in the late-1940s when one respondent worked there. The cow's milk used for artificial feeding was delivered at night by the milkman. It was boiled and modified for babies with special needs by adding lactic acid (to make lactic acid milk) or Benger's Food. Another man delivered expressed breastmilk (EBM) to the MCW homes, and this also was brought to the boil before being fed to the babies $^{1}$ (yet boiling destroys most of the immune factors in breastmilk).

\section{Sick babies and problem feeders}

Mothers of premature or weak babies who survived were encouraged to provide breastmilk for their babies. A Brisbane mother's third pregnancy resulted in the birth of undiagnosed premature twins, a boy and a girl, in the Brisbane Women's Hospital in 1952. While the babies remained in hospital, their mother expressed her milk, which her husband took to the hospital each day in a two-pound honey jar.

After the babies were discharged, they were breastfed concurrently for some time and a clinic sister made weekly home visits. One week, she brought a young doctor, who planned a blood test the next week. Luckily an experienced neighbor was concerned about the babies' poor color and helped the mother take the babies to the Children's Hospital by bus and tram. On admission, each twin needed an immediate blood transfusion. After that, the mother lost faith in the MCW staff. Despite being one of 12 children and already being a mother, she had not realized that the twins were anemic. For two years the babies were closely monitored by a leading pediatrician at the Children's Hospital (pp 161-162). ${ }^{1}$

In 1961 another Brisbane mother's sick firstborn received care from a specialist pediatrician. The baby was too weak to breastfeed and the mother expressed her milk. The child was readmitted to the Brisbane Children's Hospital within $48 \mathrm{~h}$ of discharge from the Women's Hospital, as this was the mother who refused the option of entering an MCH home for feeding difficulties. The nurses in the babies' ward at the Children's Hospital encouraged her to express and bring her EBM to the hospital each day and, when her daughter was well enough, the nurses helped her establish breastfeeding. She eventually breastfed this baby for six months, longer than her two healthy babies. She attended both the baby clinic and her local doctor with her second and third babies, though she used the clinic only to have the 
baby weighed as she disagreed with the ideology of treating all babies exactly the same.

Several babies in a family of eight had difficulty breastfeeding effectively, starting with the first, born in Nurse Bade's private hospital in Nambour in 1940. When he was unable to feed from his mother, Nurse Bade asked another patient to breastfeed him, also unsuccessfully. A technique, later named dancer hand technique, ${ }^{36}$ was used to support the baby's chin and face to improve his feeding, but to no avail (two graduates from the 1946 MCW training course described similar techniques). This baby's weight plummeted by $30 \%$ before his first visit to the baby clinic. ${ }^{37}$ His mother found support from the clinic sisters invaluable at this difficult time and attended weekly. Her son began to gain weight on an artificial milk mixture. The cause was an infant oral problem, rather than any maternal inability to lactate adequately, as this mother expressed her breastmilk successfully for the next three babies, who also had an undefined suck problem. She fed them her EBM by bottle for eight months each, a commitment she was happy to fulfill. After the birth of her fifth baby, her doctor told her not to breastfeed, mistakenly believing he was doing her a favor in lessening her work (pp 163-164). ${ }^{1}$ Typically of her generation, she followed her doctor's orders without question, against her own wishes.

Medical problems sometimes meant different ways of managing babies' feeding. One family's fourth child, born in the 1950 s, required surgery for a bowel condition at eight months, and her mother provided EBM for her. A little boy in another family, born in 1954, was diagnosed with infant eczema and taken off all milk, including, surprisingly, breastmilk. He was referred to a dermatologist, who admitted him to hospital for treatment. After discharge from hospital, feeding him was difficult and involved a special food, home-made beef broth, canned evaporated milk and avoidance of eggs. Unsweetened evaporated cow's milk was considered less allergenic than fresh or dried cow's milk. The eczema eventually cleared by the age of two.

\section{Discussion}

While the MCW baby clinics were the source of advice most often mentioned, mothers' did not necessarily follow the directions. Women attended for other reasons, such as to have the baby weighed, to meet other mothers, or to discuss a personal matter with a disinterested observer. Inexperienced mothers with no family nearby depended on the clinics, at least initially. As they gained confidence, they commonly followed their own judgment. When mothers disregarded the advice, they were unlikely to tell the nurse. Those mothers who attended more than one clinic reported different experiences with different staff. Although some mothers recalled negative experiences, most mothers considered most nurses friendly. Clinic policy was to support breastfeeding, but the advice, when followed, had mixed results.

Others who provided mothers with personal advice included grandmothers and other family members, and other professionals consulted were private doctors, pharmacists and other nurses. Relations between the clinic nurses and doctors varied, and any negativity appears related to concern about maintaining professional roles.

In the years since the period of this study, the manner in which advice was provided by baby clinic nurses changed to reflect the better education among mothers and a greater understanding of listening and counseling skills. These changes were alluded to by one of the nurses interviewed, who worked for the MCW both during this period and again after a break of several years to have her own children. Having had children of my own and experienced how a mother feels, I know I could have helped some new Mums enjoy parenthood much more. During our training the emotional side was not given enough attention (p 155). ${ }^{1} \mathrm{~A}$ 2003 study by Barnes and colleagues found constant change, including role change and lack of time to build nurse-client relations, affected work satisfaction. ${ }^{38}$ They noted that the focus since the 1970s is less on surveillance, and more on a developmental and wellness model, while today at-risk clients are targeted, rather than the general population. The service is now managed regionally, instead of centrally, leading to local differences.

\section{Strengths and limitations}

The study depended largely on respondents who read newspapers and volunteered, and is limited to the experiences described by the literate, articulate women who responded. A case in point is that experience of the MCW homes is limited to those of one mother and one nurse in only one of these facilities, whereas anecdotal information suggests that mothers' views of their experiences in other homes may have been less positive. The use of dummies (pacifiers), discouraged by the MCW but often used, was not addressed. The hypothesis that mothers with tertiary qualifications might be more inclined than other women to evaluate advice and make their own decisions could not be tested as there were only two in this sample. Tertiary education for women was unusual and in the early part of this period many left school at age thirteen or fourteen. ${ }^{39}$ Nevertheless, this study includes women from most regions of the state and minority groups after gaps in representation were filled through contacting women from the author's own networks.

\section{Implications for practice}

Nurses need to be aware that attendance at a service does not necessarily equate with exactly following their advice. Health services do not operate in a vacuum as those using them are exposed to other information. This is particularly relevant today, with the increasing availability of Internet information and misinformation. This study of another era also suggests that mothers pay more heed to professional advice when they feel comfortable with the way it is provided and perceive it as relevant to their circumstances. Further research is warranted on Queensland mothers' satisfaction and compliance with advice from community child health nurses and the related telephone advice service in more recent periods. In addition, the author suggests a comparative study of demographic factors, satisfaction and compliance in Queensland mothers' use of the 24-h help lines operated by Queensland Health and the voluntary organization, the Australian Breastfeeding Association.

\section{Conclusions}

Most Queensland mothers in the post-war period, 1945-1965, had at least some contact with the state MCW baby clinics, irrespective of other sources of advice used. Attendance did not necessarily equate with compliance. Many of those who attended adapted the advice, using their own judgment as they gained confidence or listening to their mothers, other family members, family doctors and other mothers. During the period studied, the state government still aimed for universal coverage of Queensland babies by the MCW service, unlike today where the delivery of services is different and prioritises providing a service for at-risk categories.

\section{References}

1. Thorley V. Feeding their babies: infant feeding advice received by Queensland mothers in the postwar period, 1945-1965. MA thesis, Department of History. St Lucia, Queensland: University of Queensland Press; 2000. pp135-167.

2. Thorley V. Midwives, trainees and mothers: maternity hospital conditions in postwar Queensland. Birth Issues 2001;10:101-6.

3 . Thorley V. Initiating breastfeeding in postwar Queensland. Breastfeed Rev 2001;9: 21-6.

4. Thorley V. Printed advice on initiating and maintaining breastfeeding in mid-twentieth century Queensland. J Hum Lact 2003; 19:77-89. 
5. Anon. Hospital services in Queensland: ahead of other states. Morning Bulletin (Rockhampton), 4 August 1952.

6. Murphy HC. History of the Maternal and Child Welfare Service, Queensland. Queensland's Health 1963;1: 21.

7. Thorley V. Softly, softly: how the Mothercraft Association of Queensland co-existed with government policy, 1931-1961. Health History 2001;3:80-93.

8. Patrick R. A history of health and medicine in Queensland. St Lucia, Queensland: University of Queensland Press; 1987. pp 283-285.

9. Gregory H. A tradition of care: a history of nursing at the Royal Brisbane Hospital. Brisbane: Boolarong Publications; 1988. pp 85-86.

10. Queensland year books, 1945-1949. Brisbane: Government Statistician; 19461950.

11. Siskind V, Del Mar C, Schofield F. Infant feeding in Queensland, Australia: longterm trends. Am J Public Health 1993;83: 103-6.

12. Lund-Adams M, Heywood P. Breastfeeding in Australia. In: Simopoulos AP, Dutra de Oliveira JE, Desai ID, eds. Behavioral and metabolic aspects of breastfeeding. Word Rev Nutr Diet., vol. 78. Basel: Karger; 1995. pp 78, 91-92.

13. Anon. People worse off than before war. Courier-Mail, January 241945.

14. McFarlane J. Fifty years of the Maternal and Child Health Service, 1918-1968. [Brisbane]: Queensland Maternal and Child Welfare, [1968?].

15. Selby WA. An historical study of the impact on women of the Queensland Labor government's maternal and infant welfare policies 1915-1957. PhD thesis. Brisbane: Griffith University; 1991.
16. Selby W. Motherhood and the Golden Casket: an odd couple. Royal Historical Society of Queensland 1992;14:406-12.

17. Burchill E. Thursday Island nurse. Melbourne: Rigby; 1972. pp 16, 23-25, 59-60.

18. Snelgrove S. Factors contributing to poor concordance in health care. Nursing Times.net 2006;102: 28. http://www.nursingtimes.net/nursing-practice-clinicalresearch/factors-contributing-to-poor-concordance-in-health-care/203456.article Accessed: 17 August, 2012.

19. Reibel T. Diabetes in pregnancy: factors affecting compliance with treatment and management regimes for women with gestational diabetes mellitus (GDM). Western Australia: Telecom Institute of Child Health Research; May 2011.

20. Alaszewski A. A person-centred approach to communicating risk. PLoS Med 2005; 2:341.

21. Selby W. Maternity hospitals and baby clinics: A twentieth century frontier. In: Pearn $\mathrm{J}$, Cobcroft M, eds. Fevers and frontiers. Brisbane, Queensland: Amphion Press; 1990. pp 197-212.

22. Selby W. Baby clinics, infant mortality and mothers: another side of the story. Oral Hist Assoc Austr J 1993;15:64-73.

23. Mein Smith P. Mothers, babies, and the mothers and babies movement: Australia through depression and war. Soc Hist Med 1993;6:51-83.

24. Mein Smith P. Infant welfare services and infant mortality: a historian's view. Austr Econ Rev 1991;93:22-34.

25. Queensland Government. Queensland past and present: 100 years of statistics, 18961996. Brisbane: Government Statistician; 1998.

26. Queensland year book 1945. Brisbane: Government Statistician; 1946
27. Queensland year book 1946. Brisbane: Government Statistician; 1947.

28. Queensland year book 1949. Brisbane: Government Statistician; 1950.

29. Care of mother and child. Brisbane: Department of Health and Home Affairs; [195-?].

30. Cilento PD. Medical Mother's opinion. Courier-Mail, weekly columns, 1950s.

31. Isbister C. Breast feeding. Med J Aust 1954;2:486-8.

32. Hitchcock NE. Infant feeding in Australia: an historical perspective, part 2: 1900 1988. Breastfeed Rev 1990;2:72-3.

33. Spock B. Common sense book of baby and child care. New York: Duell, Sloan and Pearce: 1945, 1946.

34. Cilento PD. MS notebook, Phyllis D. Cilento Collection, Box 23, Spirex notebook, no pagination. Fryer Library, University of Queensland, UQFL93. Available from: http://www.library. uq.edu.au/fryer/ms/uqfl44.pdf

35. Cilento PD. My life. Sydney: Methuen Haynes; 1987. p 99.

36. Danner SC, Cerutti ER. Nursing your neurologically impaired baby. Rochester, New York: Childbirth Graphics; 1984. p 8.

37. Widdowson N. Couple celebrate 59th anniversary. Northwest Chronicle, n.d.; 1998.

38. Barnes M, Courtney M, Pratt J, Walsh A. Contemporary child health nursing practice: services provided and challenges faced in metropolitan and outer Brisbane area. Collegian 2003;10:14-9.

39. Queensland year book 1960. Brisbane: Government Printer; 1961. p 99. 